\title{
Preface to the Proceedings of the Vth European Information Brokers Meeting
}

The European Information Brokers Meeting is a small, but important part of Infobase, the German Electronic Information Services Conference. The Infobase exhibition consisted of approximately 200 exhibitors of which $20 \%$ were non-Germans from 12 companies. Information providers and producers count for the largest share (online approximately 40\%, CD-ROM approximately 15\%). Consultancy, brokers and other intermediaries counted for $20 \%$ of the exhibitors with the remaining part consisting of multimedia, hardware, software and groupsware companies. One of the major brokers at Infobase was WIND celebrating its 10th anniversary (see also "Ten years of WIND: an information Brokers success story").

Germany's electronic information industry grew less last year than in 1992 in both percentage and in absolute terms. A report ${ }^{1}$ presented at Infobase 94 says that sales of professional information rose by DM $117 \mathrm{~m}(11.3 \%)$ to a total of DM 1.153 billion compared to a rise of DM $127 \mathrm{~m}(14 \%)$ in 1992 . Newcomers to the German market were responsible for much of last year's growth. The estabished players, on the other hand, saw sales grow by only $6.8 \%$

Revenues for professional online information increased by $8.3 \%$ to DM $948 \mathrm{~m}$, of which half was for realtime data.

Growth for what Bredemeier calls "the classic specialist online providers" was up to $7.6 \%$ overall, but only $4.3 \%$ for those specialising in scientific and technical areas. For those offering economic information the increase was $11.1 \%$, for newswire services only $3.1 \%$, but for online credit information it was $18.8 \%$.

CD-ROM sales increased by $28.6 \%$ to a total of DM $136 \mathrm{~m}$, after having doubled to DM $106 \mathrm{~m}$ the previous year.

Major services of the infomediary, which can be offered to SMEs are:

- Problem identification and support to solve these problems;

- accessibility and availability of information;

- information technology for efficient and effective information processing;

- information technology for the support of creative and intellectual processes of the user;

- feedback and user needs.

Information providers of CD-ROM products seem to give up their reluctance to sell to information brokers at normal subscription prices and licensing agreements, just as online hosts have done in the past. This could be accelerated by using "maturing" software.

\footnotetext{
${ }^{1}$ The "Report on the condition of the German Information Industry Economy 1993/1994" costs DM 630. Information: W. Bredemeier: +49 232467009 (tel); 67006 (fax).
} 
This is one of the issues related to pricing and there are many pricing models, such as

- deposits upfront;

- per project;

- per service (element);

- per time element (hour, day, etc.).

Hans Hoppe, Managing Director, IRI Software B.V. (an Information Resources, Inc. Business), leased in Rotterdam (NL) gave an exploration of the opportunities Executive Information Systems (EIS) could offer information brokers, in support of business development ${ }^{2}$. EIS could develop new value-added services of information brokers, as was illustrated by the "information pyramid" to describe the value-added stages of the information.

IRI is a public company (NASDAC registration) with revenues of $\$ 335 \mathrm{~m}$ in 1994 (annual growth is $30 \%$ ) and a staff of 4,500. IRI is active in market research (IRI InfoScan) and software (IRI Software) to improve decision making in corporations with its EXPRESS software. EXPRESS supports Business Intelligence, which is, according to Hans Hoppe, the process of transforming data into information.

The UK has seen a slight decrease in the number of information brokers since 1991, according to Karen Beesley of INFORMED Business Services (London). She sees the provision of services to business and commerce as a major market, as well as outsourcing and recruitment.

Due to the - still - relatively low user awareness of the existence of brokers, brokers have to diversify as they cannot live on pure brokerage alone (searching, research, document delivery). They have to go into consulting, market research, seminars and software development. Other characteristics of the broker business are:

- person-related with an average of 4 staff members;

- $75 \%$ of revenues comes from "business related activities";

- most brokers are to be found in London and the South of England, $40 \%$ and $30 \%$, respectively.

Carl Welker emphasized the need for "thinking business" and business development. Brokers have to develop - as an ongoing process - new products and services to be able to stay in business. Continuity provides stability and customers like to do business with solid companies.

$\mathrm{He}$ (and other speakers) stressed the role that brokers can play in helping SMEs in developing their business, opening new markets, etc. Information brokers may contribute to the clients' value chain by keeping the client ahead through:

- providing competetive edges;

- supporting new business development;

- new business development;

- innovation support.

The demand for information brokers is expected to be high, because their clients are faced with: 
- increased product and market complexity in global business;

- increased product and market dynamics;

- industry trends to outsourcing of services;

- increasing appreciation of the value of information, notably by accountants, bankers, insurance companies, advertising, etc.

As in previous years the Marketing Swap and Shop and the social/business networking opportunities (lunch/coffee breaks, reception) have proven to be of great value to the audience.

Sponsorship of the meeting has been received from Gale Research, IAC Europe and Infobase/Messe Frankfurt.

Johan van Halm

Johan van Halm Information Consultancy

P.O. Box 688

NL-3800 AR Amersfoort

The Netherlands 